\title{
Metáfora e metonímia: o traço-de-união entre os compostos
}

\author{
Metaphor, metonymy and their relation to \\ compounds in Brazilian Portuguese
}

Alba Valéria Tinoco Alves Silva*

Universidade Federal da Bahia

Salvador - Bahia / Brasil

\begin{abstract}
RESUMO: Com o intuito de apresentar um modelo de análise de palavras compostas que seja, ao mesmo tempo, simples e abrangente, este artigo focaliza o processo de formação lexical por composição no português do Brasil sob o ponto de vista semântico. A discussão centra-se na motivação semântica da palavra composta no que diz respeito a sua importância para a economia linguística e sua articulação do ponto de vista da metáfora e da metonímia, que são as bases fundamentais do modelo aqui proposto.
\end{abstract}

PALAVRAS-CHAVE: metáfora, metonímia, formação de palavra, composto.

ABSTRACT: In order to present a simple and comprehensive model of compounds based on their meaning, this article studies the word-formation process of compounding in contemporary Brazilian Portuguese in terms of its semantics. The role and importance of compounding in systematic processes of lexical expansion is analyzed, and a semantic classification of compounds based on metaphor and metonymy is proposed.

KEYWORDS: metaphor, metonymy, word-formation, compound.

\section{Introdução}

"A hora do léxico chegou!"Com esta exclamação, Bauer (1983, p. 1) comentava, há quase três décadas, o súbito interesse dos linguistas pelo estudo do léxico, porque perceberam que a análise das formações lexicais podia esclarecer outros aspectos do funcionamento da língua. Esse campo de pesquisa, segundo ele, caracterizava-se por ser controvertido, devido à exígua base teórica e ao pouco consenso metodológico de que o assunto dispunha.

*albavaleria99@hotmail.com 
Desde então, muitos estudos têm sido empreendidos tendo como foco a formação de palavras em seus múltiplos aspectos: conceito, terminologia, produtividade, restrição, bloqueio e tantos outros. Na maioria das vezes, porém, eles estão voltados apenas para um dos processos de renovação lexical: a derivação.

Em se considerando que, no caso do português, a composição é um dos processos mais gerais de formação de palavras, que é um processo altamente produtivo, que tem por objetivo a nomeação e / ou caracterização dos seres e eventos, e que há uma notável assimetria entre a abundância de estudos lexicais voltados para a flexão e a derivação e a exiguidade daqueles dedicados à composição, a contribuição deste trabalho ${ }^{1}$ para os estudos lexicais reside, primeiramente, em desviar o foco das atenções, voltado para a derivação, para as perguntas que a composição suscita - Por que se formam compostos? Qual a razão de sua produtividade? Qual o seu papel na economia da língua? - e buscar respondê-las por meio dos pressupostos teóricos que constituem a primeira parte do trabalho, dividida em: a) a composição e a economia linguística e b) a motivação tropológica dos compostos. E, em segundo lugar, propor um modelo de classificação tropossemântica dos compostos que possa unificá-los de maneira mais abrangente do que a dos modelos já existentes. Essa parte consiste em: a) definição dos parâmetros e procedimentos metodológicos; b) análise de compostos tradicionais fundamentada no modelo proposto; e c) apresentação do resumo do modelo aplicado a compostos mais recentes.

\section{Pressupostos teóricos}

\section{A composição e a economia linguística}

A criação de uma sequência fonológica inédita na língua portuguesa, fora dos domínios da ciência e das marcas comerciais, é um fenômeno incomum. Os novos conceitos são nomeados a partir das velhas palavras de sempre. A neologia vernácula, vista assim, é um incessante processo de reciclagem que renova o léxico preservando-o, como se a língua dispusesse de

\footnotetext{
${ }^{1}$ Este artigo baseia-se em pesquisa, realizada de 2000 a 2002, no Instituto de Letras da Universidade Federal da Bahia, para a elaboração da dissertação de mestrado homônima, sob a orientação do Prof. Dr. Décio Torres Cruz e coorientação da Profa. Dra. Serafina Pondé.
} 
um movimento de ecologia linguística como parte integrante de sua economia.

No português, de acordo com Basílio (2007, p. 10), as razões para a formação neológica e seus modos principais de articulação são:

1) a mudança de classe, quando o conteúdo semântico de uma palavra do léxico é transposto para uma outra de classe diferente; o acréscimo, por exemplo, do sufixo -ção ao verbo democratizar forma o substantivo democratização;

2) o acréscimo de um traço semântico ao significado básico de um item lexical, como por exemplo, uma dimensão pequena (prato / pratinho), uma dimensão pejorativa (livro / livreco), uma indicação de anterioridade (fabricado / pré-fabricado);

3) e a terceira razão subjacente, como já se disse, é a economia linguística, uma vez que um sistema linguístico com uma palavra nova para cada classe gramatical e para cada acréscimo semântico seria inexequível.

Analisando-se a primeira razão, percebe-se que ela é característica apenas da formação de palavras por derivação sufixal, pois tanto a derivação por prefixação quanto a composição não provocam mudança de classe.

Quanto ao acréscimo semântico, em pares como mala / malinha, carro / carrão, filme / filmaço, filme / filmeco, estando presente no sufixo uma intenção pejorativa, admirativa ou meramente descritiva em relação ao tamanho do objeto, ambas as opções se referem, geralmente, ao mesmo objeto. Existe um grau de acréscimo ao significado básico, mas a referência permanece a mesma. No caso dos prefixos, em pares como computador / microcomputador, saia / minissaia, ainda, genericamente, pode-se dizer que ambos os pares se referem, basicamente, ao mesmo objeto. Já em pares como mala / porta-mala, carro / carro-de-mão, tem-se dois objetos diferentes.

Com isso, pode-se dizer que o acréscimo semântico Stricto sensu é próprio da derivação. Na composição, cuja função principal é a nomeação ou caracterização dos seres, o acréscimo semântico ocorre em grau máximo, provocando o desvio, às vezes total, da referência inicial para uma nova, realizando, assim, sua função de nomeação. No caso de sofá-cama, por exemplo, a composição é o resultado do acréscimo de traços semânticos da referência cama ao de sofá. Mas, em louva-a-deus, olho-de-sogra, olho-mágico, pé-de-cabra, o desvio é total. Normalmente se diz, nesses casos, que a soma das partes não é o significado. E isso, voltando a Basílio (2007, p. 31), não 
acontece por acaso. O distanciamento, muitas vezes verificado, entre o significado global de uma formação lexical e a função do significado de seus componentes, seja uma derivação ou uma composição, é decorrente de diversos fatores, como a evolução semântica em desacordo com a permanência morfológica, a multiplicidade de processos que podem afetar uma construção, utilização e disseminação de situações naturais de metáfora e extensão de sentido. No caso da composição, entretanto, esse distanciamento é quase norma, não podendo ser considerado como caso de exceção.

Pelo que acabou de ser visto, são pertinentes as perguntas:

1) por que se formam palavras compostas?;

2) qual a razão da produtividade de um mecanismo que não permite nem a mudança de classe nem o acréscimo semântico?;

3) como caracterizar um processo de formação lexical que parece infringir as leis da economia linguística, uma vez que o significado de seus exemplares normalmente se afasta do significado de suas partes componentes?

Para respondê-las, vale ressaltar o papel fundamental da palavra complexa, seja ela derivada ou composta, na economia linguística, descrito por Guilbert (1975, p. 61) ao dizer que novas palavras são formadas principalmente a partir de palavras já existentes na própria língua ou tomadas de empréstimo de uma outra língua-mãe. Essa filiação, segundo ele, é necessária para tolher a invenção demasiada e serve, portanto, como um mecanismo de segurança para a comunidade e o falante.

Esse argumento, que alude ao princípio básico da economia linguística, é corroborado por Basílio (2007, p. 10) ao dizer que "o mecanismo da língua sempre procura atingir o máximo de eficiência, o que se traduz num máximo de flexibilidade em termos de expressão simultaneamente a um mínimo de elementos estocados na memória". O que ela chama de flexibilidade e o que Guilbert chama de mecanismo de controle protegem o sistema linguístico do excesso de arbitrariedade, tornando-o mais econômico e versátil.

Ainda a propósito das palavras complexas, Bauer (1983, p. 142-143) salienta os seguintes aspectos do seu conteúdo semântico:

1) os lexemas motivados agem melhor como dispositivos mnemônicos do que os não-motivados;

2) uma vez que os lexemas complexos são tidos como mnemônicos motivados, um certo laconismo na sua informação semântica faz sentido. 
3) o papel dos lexemas complexos não é o de prover uma descrição exaustiva do que quer que nomeie, mas o de remeter, da maneira mais concisa possível, a algum traço relevante do denotatum.

Sendo uma palavra complexa por excelência, tudo que foi dito até aqui é particularmente relevante para a palavra composta e permite que se respondam as duas primeiras perguntas formuladas anteriormente. Os compostos são formados porque, entre a infinitude da realidade extralinguística a ser nomeada e a finitude de elementos de uma língua, eles encontram a sua razão de ser, que é a de dar nome aos seres pela junção, grosso modo, dos nomes de outros seres, aludindo de alguma forma, seja de maneira descritiva ou figurativa, ao que está sendo designado. A produtividade de construçôes como sofá-cama, porta-mala, pé-de-moleque se justifica, porque sua estrutura e significação garantem a filiação a outras palavras da língua de que fala Guilbert, como também o dispositivo mnemônico entre o signo e o objeto que designam, como mencionado por Bauer.

Tais argumentos atribuem ao composto um papel realmente significativo no funcionamento da língua. Graças a eles, o que antes foi chamado de irregularidades - como a assimetria da estrutura e o distanciamento entre estrutura e significado - que pareciam ferir os princípios da economia linguística, agora podem ser vistos como componentes formadores de dispositivos mnemônicos, assim estruturados por exigência dessa própria economia, o que responderia à terceira questão formulada.

Contudo, mesmo sendo a motivação mnemônica a razão de cada formação composta, isso não esgota a questão, porque, ainda que todos os exemplos possam ser vistos como um lembrete do denotatum, a articulação desses lembretes é muito diversa para que eles possam ser agrupados indiferentemente. Em sofá-cama, por exemplo, a articulação do lembrete se dá pela descrição de características mais diretamente perceptíveis no objeto do que aquelas presentes em $p e ́$-de-moleque, que se define, por isso, como uma nomeação figurada ou metafórica. São esses modos de articulação que serão analisados, a seguir.

\section{A motivação metafórica e metonímica dos compostos}

Basílio (2007, p. 31-34) diz que a nomeação dos seres, com exceção dos casos de nomeação acidental ou arbitrária, pode ser descritiva ou metafórica.

Na nomeação descritiva, um ser, um objeto, um evento é designado em termos de suas características objetivas mais relevantes. Inúmeros exemplos de 
nomeação descritiva são encontrados entre as composições do tipo $S+S,{ }^{2}$ em que o primeiro termo é o núcleo da construção, o segundo termo é o especificador ou modificador, em exemplos como sofá-cama e papel-aluminio. Outras formas de nomeação descritiva seriam os compostos formados por um substantivo e um adjetivo, em que o substantivo é o núcleo e o adjetivo, o especificador, não importa a ordem: belas-artes, caixa-alta, livre-arbitrio; os compostos de verbo + substantivo, em que o segundo termo é o objeto direto do primeiro: guarda-roupa, mata-mosca e os de estrutura $S+\mathrm{de}+\mathrm{S}$, como águade-cheiro.

Na nomeação metafórica, por sua vez, o objeto é denominado não por características objetivas, mas por conta de propriedades transferidas em termos associativos. Em louva-a-deus, por exemplo, a postura do inseto lembra alguém em oração. Há ainda a nomeação mista, como em peixe-espada, em que o peixe é descrito metaforicamente.

$\mathrm{Na}$ classificação semântica dos compostos proposta por Basílio, o composto metafórico abarca exemplos distintos em termos de associação figurada, como louva-a-deus, em que a postura do inseto lembra a de alguém orando, o que seria de fato metafórico, e bóia-fria, em que o indivíduo é assim chamado porque come a comida (bóia) fria, o que o tornaria um exemplo de estrutura metonímica. De modo que é preciso analisar a questão um pouco mais a fundo.

Bauer (1983, p. 30) distingue quatro tipos de compostos:

Os substantivos compostos podem ser, ainda, subdivididos em quatro grupos de acordo com critérios semânticos. Considerem-se, primeiramente, os exemplos beehive, armchair, redskin, highbrow, maidservant. Todos eles podem ser subdivididos em um segundo elemento, que é o núcleo gramatical (este é o elemento marcado pelo número e é, também, em línguas que tem gênero gramatical, o elemento que determina o gênero do composto) e um primeiro elemento que é o elemento modificador (que não é marcado por número e não determina gênero). Nos primeiros dois exemplos, o composto é um hipônimo do núcleo gramatical: beehive é um tipo de

${ }^{2}$ No corpo do trabalho foram utilizadas as seguintes abreviaturas: $\mathrm{A}=$ adjetivo; Adv = advérbio; $\mathrm{S}=$ substantivo $\mathrm{V}=$ verbo; $\mathrm{NUC}=$ núcleo; $\mathrm{DET}=$ determinante. 
hive, armchair é um tipo de chair. Este tipo de composto é chamado de composto endocêntrico. ${ }^{3}$

No português, esse tipo de composto é o do tipo $S+S$ subordinativo, em que o primeiro elemento é o núcleo e o segundo, o determinante. Do ponto de vista semântico, alguns deles são hipônimos de um núcleo genérico, como é o caso de peixe-espada, peixe-boi, peixe-lua, hipônimos de peixe.

O segundo tipo de composto depreendido por Bauer (1983, p. 30) é:

Nos dois segundos exemplos [redskin e highbrow], o composto não é um hipônimo do núcleo gramatical: redskin não é um tipo de skin, nem highbrow é um tipo de brow. Este tipo de composto, denominado composto exocêntrico (ou às vezes composto bahuvribi, usando a terminologia do sânscrito), é o hipônimo de um núcleo não-expresso ('pessoa' em ambos os exemplos dados aqui). Uma vez que o núcleo semântico não está expresso em tais compostos, o composto normalmente é visto como metafórico ou sinedóquico. ${ }^{4}$

Nos compostos exocêntricos, o centro não está presente. O composto inteiro se refere, metafórica ou sinedoquicamente, a um núcleo não expresso. É o caso, em português, por exemplo, de beija-flor.

O terceiro tipo proposto por Bauer (1983, p. 30) é:

\footnotetext{
3 "Compound nouns can be further subdivided into four groups according to semantic criteria. Consider first the examples beehive, armchair, redskin, highbrow, maidservant. These can be all subdivided into a second element, which is the grammatical head (this is the element marked for a number, and also, in languages which have grammatical gender, the element which determines the gender of the compound) and a first element which is the modifying element (which is not marked for number and does not determine gender). In the first two examples, the compound is a hyponym of the grammatical head: a beehive is a kind of hive, an armchair is a kind of chair. This type of compound is termed an endocentric compound." (T. A.). 4 "In the second two examples [redskin and highbrow], the compound is not a hyponym of the grammatical head: a redskin is not a type of skin, nor is a highbrow a kind of brow. This kind of compound, termed an exocentric compound (or sometimes a bahuvrihi compound, using the Sanskrit terminology), is a hyponym of some unexpressed grammatical head ('person' in both examples given here). Since the semantic head is unexpressed in such compounds, the compound is frequently seen as metaphorical or synecdochic". (T.A.).
} 
Em terceiro lugar, maidservant é um hipônimo de ambos maid e servant: maidservant é um tipo de maid e também um tipo de servant. Este tipo de composto é chamado de composto aposicional. ${ }^{5}$

Esse tipo de composto, muitas vezes, coincide com a estrutura $S+S$ coordenativa, em que não existe entre as duas partes uma relação NUC-DET ou DET-NUC, por exemplo, cantor-compositor e copeira-faxineira.

E, finalmente, a última categoria da tipologia de Bauer (1983, p. 30-31) é:

A divisão final de substantivos compostos é exemplificada por AlsaceLorraine e Rank-Hovis. Aqui não está claro que elemento é o núcleo gramatical, e o composto não é um hipônimo de nenhum elemento, mas os elementos nomeiam entidades distintas que se combinam para formar a entidade denotada pelo composto. Este tipo de composto normalmente recebe o nome em sânscrito de dvandva, embora o termo em inglês composto copulativo seja também usado para descrevê-lo. ${ }^{6}$

Bauer (1983, p. 203) acrescenta que esse último tipo de composto, quando formado por dois substantivos comuns, nunca foi muito encontradiço no inglês, mas que as fusões empresariais continuam fornecendo exemplos com substantivos próprios, como é o caso de Cadbury-Schweppes, Rank-HovisMcDougal, Rowntree-Mackintosh.

Sandmann (1992), que é o terceiro autor a ser analisado, utiliza elementos das duas classificações anteriores, propondo um modelo tropológico mais abrangente para os compostos, visto que faz uma distinção entre os compostos metafóricos e metonímicos.

De acordo com ele, metafóricos são os compostos em que a transferência do significante de um signo linguístico para outro referente baseia-se na semelhança entre os referentes, por exemplo: copo-de-leite "flor", perna-de-moça "tipo de pescada", pente-fino "operação policial", peixe-espada. Sandmann

5 "Thirdly, maidservant is a hyponym of both maid and servant: a maidenservant is a type of maid and also a type of servant. This type of compound is termed an appositional compound". (T.A.).

6 "The final division of compound nouns is exemplified by Alsace-Lorraine and Rank-Hovis. Here is not clear which element is the grammatical head and the compound is not a hyponym of either element, but the elements name separate entities which combine to form the entity denoted by the compound. This type of compound is normally given the Sanskrit name of dvandva, although the English term copulative compound is also used to describe them". (BAUER, 1983, p.30-31) (T. A.). 
salienta o fato de que, nos três primeiros exemplos, o composto todo é metafórico, enquanto, no último exemplo (peixe-espada), só o adjunto espada é metafórico, que é o mesmo caso de trem-bala e remédio-porrete.

Quando a transferência do significante de um signo linguístico para outro referente se dá baseada na contiguidade ou na coocorrência espaçotemporal dos referentes, ou seja, na contiguidade física, tem-se um composto metonímico: $($ Ele come $)$ bóia fria $=($ Ele é um) bóia-fria, $($ Ele tem $)$ cara-pálida $/$ pele-vermelha $=($ Ele é um) cara-pálida / pele-vermelha. Outros exemplos seriam: beija-flor, mão-pelada, boina-verde, gola-vermelha, dedo-duro, etc.

Um outro aspecto da classificação de Sandmann diz respeito ao núcleo da composição, cuja presença ou ausência distingue, respectivamente, os compostos endocêntricos dos exocêntricos. Cotejando dois nomes de peixe - perna-de-moça e peixe-agulha-, ele chama o composto peixe-agulha de endocêntrico, pois apenas o adjunto agulha é usado figurada ou metaforicamente. Já em perna-de-moça em que a sequência toda é empregada metaforicamente, o composto é exocêntrico. Quanto aos compostos metonímicos, como beijaflor, mata-burro, barriga-verde, pé-de-meia, chapa-branca "automóvel oficial", mão-aberta, mão-fechada, Sandmann considera-os todos metonímicos e exocêntricos, casos em que "a contiguidade é a parte ou o caminho que nos leva a associar a expressão complexa com o referente” (1992, p. 42-44). Vale ressaltar que perna-de-moça é considerado como sendo metafórico e exocêntrico e pé-de-meia, como sendo metonímico e exocêntrico, donde se conclui que a motivação metafórica dos compostos é independente de sua estrutura morfossintática.

Por fim, antes de passar ao modelo que será aqui proposto, vale ressaltar o status de papel principal atribuído, por Azeredo (2008, p. 446-448), à metáfora eà metonímia no modo como os compostos se referem às entidades que designam. Segundo o autor, o composto é do tipo metonímico quando a entidade à qual se refere é identificada por sua utilidade, função (saca-rolha, quebra-mar) ou qualquer característica tipificadora (cara-de-pau, dedo-duro). O composto metafórico, por sua vez, é aquele cuja entidade referida é nomeada com base numa relação de semelhança: espada-de-são-jorge (planta de talos semelhantes a espadas), péde-galinha (rugas localizadas na extremidade externa do olho), entre outros.

Estabelecida, pois, a motivação tropológica dos compostos, o que se quer propor em termos de uma nova classificação é:

a) na classificação de Sandmann, há dois subtipos para o composto metafórico e apenas um subtipo para os metonímicos, questiona-se se o conceito de 
metonímia é incompatível com a presença do núcleo para que se mantenha esse modelo instável, e propõe-se um modelo que equilibre os compostos metonímicos;

b) as classificações de Basílio e Bauer incluem, de alguma forma, os compostos considerados não-metafóricos ou descritivos, mas estes não são mencionados por Sandmann; no novo modelo, tais compostos são considerados como sendo tropologicamente motivados;

c) as classificações de Basílio e Sandmann são exemplificadas com composiçóes já lexicalizadas; o novo modelo será exemplificado com formações linguísticas mais recentes.

\section{Proposta do modelo}

\section{Parâmetros e procedimentos metodológicos}

O esboço do modelo para análise de seus parâmetros é o seguinte:

\begin{tabular}{|c|c|}
\hline COMPOSTOS DE INVENÇÃO & COMPOSTOS DE USO \\
Metafóricos & Metafóricos \\
In absentia & In absentia \\
In praesentia & In praesentia \\
Metonímicos & Metonímicos \\
In absentia & In absentia \\
In praesentia & Inpraesentia \\
\hline
\end{tabular}

Os parâmetros mais amplos desse modelo foram baseados em Paschoal (1990, p. 119-122), que retoma aspectos da retórica clássica, articulando-os da seguinte forma:

1) metáforas mortas ou de uso são as lexicalizadas e metáforas novas ou de invenção são as recém-saídas do discurso;

2) metáforas in praesentia são aquelas com teor e veículo ${ }^{7}$ presentes e metáforas in absentia são aquelas cujo veículo está presente, e o teor, ausente.

${ }^{7}$ A terminologia - teor e veículo - foi proposta por I. A. Richards em sua obra The Philosophy of Rhetoric (Oxford University Press, 1936). 
Os termos "teor" e "veículo" designam duas partes integrantes da metáfora, sobre as quais Ricoeur (2005, p. 129-130) esclarece:

I. A. Richards propôs designar por 'teor' (tenor) a idéia subjacente, e por 'veículo' (vehicle) a idéia sob cujo signo a primeira é apreendida. Mas importa notar que a metáfora não é o 'veículo’: é o todo constituído pelas duas metades.

Estabelecendo uma relação entre esses pressupostos e a definição de metáfora aplicada aos compostos, ou seja, a transferência do significante de um signo linguístico para outro referente com base na semelhança entre os referentes (Cf. SANDMANN, 1992, p. 42-43), tem-se que em um composto como tatu-bola, "teor" é o referente - representado in praesentia pelo seu respectivo significante tatu - sobre o qual a transferência vai atuar por meio de um "veículo", no caso bola. A base de similaridade entre esse "teor" e esse "veículo" está na forma arredonda presente no objeto bola e também no animal tatu quando se enrola sobre si mesmo. Já em copo-de-leite "flor", a sequência inteira é tomada metaforicamente, nesse caso apenas o "veículo" está presente, cabe ao falante descobrir qual é o "teor" e qual a base de similaridade entre ambos que justifique a metáfora.

Relacionando, por fim, esses dois conceitos às noções de endocentrismo e exocentrismo vistas em Bauer e Sandmann, endocêntricos seriam os compostos com teor in praesentia e exocêntricos, aqueles com teor in absentia.

Essas mesmas considerações são válidas para a metonímia, sendo que, nesse caso, a transferência do significante de um signo linguístico para outro referente se dá baseada na contiguidade ou na coocorrência espaço-temporal dos referentes, ou seja, na contiguidade física (Cf. SANDMANN, 1992, p. 42-43).

Outro parâmetro a ser aplicado aos compostos é a oposição De Uso x De Invenção. Os Compostos de Uso são os lexicalizados e / ou dicionarizados, que serão exemplificados por compostos retirados de dicionários e / ou das obras de referência aqui citadas. Os Compostos de Invenção são aqueles de produção mais recente, presentes mais no discurso do que nos dicionários. Para exemplificá-los, conta-se com um corpus escrito, representativo da norma comum, qualitativo, constituído especificamente para testar a validade do modelo em formações compostas mais recentes da língua. Optou-se pela modalidade escrita do código, porque nela, pela presença do hífen, os compostos se tornam particularmente depreensíveis. No que se refere à norma, tendo em vista que o objetivo do trabalho é construir um modelo de 
classificação de compostos abrangente, optou-se por fontes vazadas na norma comum.

Para a obtenção dessas características, a escolha das fontes da pesquisa recaiu sobre jornais e revistas de circulação e representatividade nacional e voltados para públicos de interesses diversos, no caso: Folha de S. Paulo, Jornal do Brasil, O Globo, Gazeta Mercantil, Veja, do período de dezembro de 1998 a dezembro de 2001.

Tendo sido explicada a estruturação dos parâmetros, passar-se-á à análise do modelo para os Compostos de Uso e depois para os Compostos de Invenção. Ao longo da análise de cada tipo, os parâmetros que norteiam sua classificação serão justificados.

\section{Análise de compostos mortos ou de uso fundamentada no modelo proposto}

\section{Composições metafóricas in praesentia}

As construçôes do tipo peixe-espada, chave-estrela, tatu-bola, couve-flor são o melhor exemplo desse tipo de composto, pois nelas "existe a aproximação aparentemente impossível de dois termos - teor e o veículo - por uma relação de similaridade" de que fala Paschoal (1990, p. 119-122). Cabe ao falante descobrir a base da similaridade entre o teor e o veículo, ou seja, o que existe de semelhante entre um peixe e uma espada ou um tatu e uma bola.

Os exemplos citados inicialmente são todos do tipo $S+S$ subordinativo, mas a classificação se presta também para as composições do tipo $S+d e+S$, como cara de bolacha, nariz de tucano, orelha de abano, boca-de-moela. São todos casos de comparação figurada compacta, composiçôes metafóricas, portanto.

\section{Composições metafóricas in absentia}

Neste grupo, tem-se o veículo da metáfora, mas não se tem o teor nem a base de similaridade que a motivou, como é o caso de olho-de-sogra, pé-decabra, louva-a-deus. Diz-se que nesse tipo de composição que a soma das partes não é igual ao todo, quando, na verdade, as partes, ou seja, os outros elementos da comparação, não estão de fato presentes. Esse grupo inclui muitas das composições metafóricas por extensão de sentido, como banho-de-cuia e caixapreta. Esses exemplos possuem moldes de estruturação que implicam uma relação de subordinação entre núcleo e determinante como $S+d e+S$, em banho- 
de-cuia, e S+A em caixa-preta, porém do ponto de vista semântico essa relação não se sustenta, uma vez que é o composto como um todo que denomina uma determinada entidade que não corresponde àquela descrita pelos elementos da mesma composição se considerados independentemente.

\section{Composições metonímicas in praesentia}

Podem ser exemplificadas por construções como navio-escola, sofá-cama, samba-canção, samba-enredo.

Os argumentos a favor dessa classificação são de Le Guern, a propósito da metonímia na formação do léxico, que podem ser resumidos assim:

a) o objeto sem nome será designado por um outro em estreita ligação com aquele, desde que o contexto elimine a possibilidade de confusão entre ambos;

b) a designação de um objeto sem nome pode ser feita por uma perífrase, mas este é um processo anti-econômico, que prejudica a comunicação. Melhor será designá-lo por um outro objeto que tenha com ele uma relação evidente (Cf. LE GUERN, 1973, p. 121-137).

Para se compreender o conceito de composição metonímica in praesentia, é necessário imaginar que exista um objeto sem nome $\mathrm{X}$, que possua características marcantes de outros objetos: $Y$ (por exemplo, um sofá) e Z (por exemplo, uma cama). Criar uma designação completamente inédita é perfeitamente possível, porém antieconômico. Designá-lo apenas por Y (sofá) ou Z (cama) causará confusão entre este ou aquele e o objeto X em questão. Portanto, de acordo com Le Guern, mutatis mutandis, o objeto sem nome $(\mathrm{X})$ será designado pela junção dos nomes de dois outros objetos $(\mathrm{Y}-\mathrm{Z})$ em estreita ligação com aquele, para que o contexto elimine a possibilidade de confusão entre os três. Pode-se dizer, ainda, que nem $\mathrm{Y}$ nem $\mathrm{Z}$ individualmente têm todas as características do objeto $\mathrm{X}$. Cada uma das partes da composição Y-Z contribui com uma parcela dos traços semânticos de X (sofá-cama), a soma das duas partes é que pode designar o todo. Assim, no caso de sofá-cama, sambaenredo, navio-escola, ambas as partes estão presentes.

Observe-se que os exemplos citados para esse caso são aqueles do tipo $S_{+} S$ subordinativo, em que existe uma relação NUC-DET, mas supõe-se que ele abranja também os do tipo $S+S$ coordenativos, como é o caso de cantorcompositor, copeira-faxineira. 
Essa categoria vale também para os compostos do tipo $S+S$ (DETNUC) espaçonave e para compostos cuja estrutura contém bases nãoautônomas, geralmente originárias de fonte erudita, grega ou latina, e por isso são chamados de neoclássicos (Cf. BAUER, 1983, p. 216), tais como tomaticultura e proctologista. Um outro grupo que também pode ser aí incluído é o dos hipônimos construídos com a estrutura $S+d e+S$, por exemplo, os seguintes hipônimos de cadeira: cadeira de balanço, cadeira do papai, cadeira de dentista. São nomeações mais específicas construídas metonimicamente por colocar em relevo uma característica, função, ou um traço qualquer que as distingue das demais.

Em relação a esse traço distintivo, vale ressaltar a afirmação de Lakoff e Johnson de que na metonímia existe uma função referencial básica, mas também a função de prover entendimento. Por exemplo, quando alguém diz "precisamos de mais cabeças nesse projeto", esse alguém não está referindo-se apenas a pessoas, e sim a pessoas inteligentes. Então, não se trata apenas de "a parte pelo todo" - que seria meramente referencial - mas ao tipo de parte à qual se está referindo. É uma questão de foco de percepção e, principalmente, do que é significativo em cada cultura (Cf. LAKOFF; JOHNSON, 2002, p. 91-98).

\section{Composições metonímicas in absentia}

Os exemplos mais ilustrativos têm estrutura do tipo $\mathrm{V}+\mathrm{S}$, como guardaroupa e porta-copo.

No caso da composição metonímica in absentia, como porta-copo, mata-mosca, podem-se usar os mesmos argumentos utilizados no item anterior e mais a presença da elipse, característica da metonímia, como foi visto.

Desse modo, nos casos da denominação do "objeto X que serve para portar Z" (porta-copo, por exemplo) ou do "objeto X que serve para matar Y" (mata-mosca), tem-se a elipse do sujeito e, por alguma razão, a inexistência de uma nomeação que lhe seja particular. Nesses casos, o objeto é designado por sua função para com outro ao qual está estreitamente ligado.

Outros exemplos de composição metonímica in absentia são aqueles, propostos por Sandmann (1992, p. 41-43), em que a transferência do significante de um signo linguístico para outro referente se dá baseada na contiguidade física: são os casos de bóia-fria, cara-pálida, pele-vermelha, mãopelada, boina-verde, gola-vermelha, dedo-duro. Em resumo, o objeto pode ser designado por um aspecto relevante, como uma função: o [objeto que] portamala; o [objeto / produto que] mata-mosca; um objeto: o [que usa] boina- 
verde; uma característica: o [carro que tem] zero-quilômetro; a frase inicial, no caso de oraçóes e jogos que são designados pelas palavras introdutórias, como pai-nosso, ave-maria, qual-é-a-música, a-baratinha-voou.

\section{Resumo do modelo aplicado aos compostos novos ou de invenção}

Compostos novos ou de invenção - São aqueles de produção mais recente, presentes mais no discurso do que no dicionário.

Metafóricos - São aqueles que se utilizam do recurso metafórico de aproximar teor e veículo por alguma relação de similaridade.

In Praesentia (Endocêntricos) - São aqueles em que o teor e o veículo estão presentes e a transferência metafórica acontece pela base de similaridade existente entre ambos, e é percebida pelo falante. Vale ressaltar que, no caso dos compostos mortos, cujo uso já está difundido na língua há muito tempo, na maioria das vezes, essa percepção não é ativada, porque a estranheza da relação metafórica já se desgastou. No caso dos novos, essa percepção é fundamental. A compilação de (01) vermelho-tango, por exemplo, se deu porque ao que se entende por "vermelho" pode ser associado às ideias de intensidade, sedução, paixão, que são características que se atribuem ao "tango". O mesmo se dá com lilás executivo, pela ideia de elegância e sobriedade e rosa-babado, de feminilidade.

Já em Preto Ninja, o que se tem é um composto de motivação metafórico-metonímica. Metonímica por uma relação de contiguidade, uma vez que preto é supostamente a cor com a qual um guerreiro ninja se veste. Mas, sobretudo, metafórica, pois, em se tratando de um catálogo de cores para o lançamento de uma nova linha de automóveis, o que se pretende, provavelmente, é relacionar a essa cor - e aos carros que a possuem - as ideias de força, agilidade, mistério associadas ao ninja.

Conquanto esse hibridismo tenha sido percebido, ele não está explicitado no modelo, porque, para cada caso analisado, está sendo levado em consideração apenas o aspecto tropológico mais significativo.

Do mesmo modo, os exemplos (03) e (04) podem ser considerados metafóricos, porque neles estão implícitas comparações por uma percepção de semelhança: atitude [como quem diz:] 'eu não faço parte do sistema'e um efeito [como se fosse uma] 'mulher-emergindo-de-bloco-de-gelo'.

(01) "vermelho-tango [no vestido] da Buganvília; azul-digital, na calça; rosababado, na saia de crepe de seda; lilás-executivo, no terno..." (Jornal do Brasil, 28/01/01, p. 37) [Reportagem sobre as novas cores da moda]. 
(02) “Branco Geada; Cinza Urano; Preto Ninja; Vermelho Tornado."(Catálogo de Cores e Acabamento - Linha Volkswagen, 2001).

(03) "Elas têm um ar moderno e uma obrigatória atitude 'eu não faço parte do sistema' que pode aparecer numa bainha descosturada, numa estampa inusitada ou no caimento improvável da saia."(Veja, 02/05/01, p.76).

(04) "Caio Gobbi que hoje veste Adriane Galisteu e Eliana lembra-se de um efeito 'mulher-emergindo-de-bloco-de-gelo' em que sua modelo vestia blusa de organza transparente cuja gola ia do pescoço à testa." (Veja, 02/05/01, p.76).

In Absentia (Exocêntricos) - Neste caso, o núcleo ou o teor da metáfora não se faz presente. O composto inteiro é o veículo da metáfora, que se dá por extensão ou transferência do significante de um signo linguístico para outro baseado na semelhança entre os referentes.

Conquanto se tenha dito que os Compostos novos ou de invenção são aqueles presentes mais no discurso do que no dicionário, todos os exemplos citados abaixo já estão registrados no Aurélio Séc. XXI. Entretanto, mesmo não sendo compostos inéditos, cada um deles possui, no seu respectivo contexto, uma acepção metafórica no uso que diverge daquela que está dicionarizada. $\mathrm{O}$ exemplo (05) caixa preta está registrado no Aurélio Séc. XXI com hífen e com o sentido geral de "sistema cujas funções externas são desconhecidas". No exemplo em questão, a expressão é aplicada, nesse caso por extensão de sentido, à contabilidade financeira do FMI cujo funcionamento é desconhecido para o público externo. O item (06) montanha-russa, cuja acepção mais geral é a de "um tipo de aparelhagem lúdica de parques de diversóes", refere-se no contexto aos bons (altos) e maus (baixos) momentos de um relacionamento, numa referência ao modo de funcionamento do brinquedo em questão.

(05) "Como ninguém entende nem jamais foi informado com transparência quanto às contas escondidas na caixa preta do FMI..." (Jornal do Brasil, 27/08/00, p.10).

(06) "A montanha-russa do namoro virou chacota entre os colegas." (Folha de $S$. Paulo, 27/08/00, cad. C3).

Metonímicos - São os que se utilizam de recursos da metonímia, como elipse e contiguidade.

In Praesentia - Ambos os elementos do composto funcionam como teor da metonímia. O seu veículo está na interseção (ou união) dos traços semânticos 
das partes componentes de formas, como assuntos-tabu, favela-bairro, unidas para designar um outro todo. Outros exemplos, seguindo esse mesmo critério, mas com outra estrutura, são os compostos neoclássicos, como legislocratas ou narcotráfico.

(07) "Ele criou a favela-bairro, projeto que tem por objetivo transformar todos os bairros da cidade em favelas." (O Globo, 27/08/00, Segundo Caderno, p.12).

(08) "para cada obra desenvolve uma solução diferente [... como fez numa treliçadivisória no Itamaraty." (Gazeta Mercantil, Sexta-feira 25 e Fim de Semana 26 e 27/08/00, p. 1).

(09) "Eu tratava de assuntos-tabu na época, como educação sexual, mas agora os pais estão mais esclarecidos e isso já não tem mais mistério." (Gazeta Mercantil, Sexta-feira 25 e Fim de Semana 26 e 27/08/00, p. 15).

(10) "Fidel convocou-o [Kevin Costner] ao Palácio da Revolução, submetendoo a sete horas (em horas-Fidel, coisa de minutos) de conversa."(Veja, 18/ 04/01, p.88).

(11) "O Congresso Norte-Americano aprovou o Plano Colômbia que prevê a aplicação de US\$ 1,3 bilhão no combate ao narcotráfico..." (Folha de S. Paulo, 27/08/00, cad. A27).

(12) "Pois os legislocratas da Agência de Vigilância Sanitária já enfiaram no seu governo dois atos inspirados na vontade de censurar a expressão alheia." (Folha de S. Paulo, 27/08/00, p. A15).

In Absentia - Neste tipo de composto, um objeto ou ser, que seria o núcleo ou teor da metonímia, está elíptico e é designado por uma função, uma parte ou uma característica relevante do recorte da realidade em questão. Essas designações exprimem a percepção daquilo que o falante considera relevante na realidade observada, omitindo o "todo" e pondo em relevo a parte que interessa. Essa "parte” pode ser representada por várias instâncias: uma função: o [veículo que] cata-mendigos; o modo de funcionamento ou tamanho do objeto: os [aparelhos] eletroportáteis, eletroeletrônicos; ou ainda, no caso do personagem "Valdemort" do livro de Harry Potter, que nunca é chamado pelo nome, mas todos sabem de quem se está falando, ser designado por "VocêSabe-Quem”.

(13) "Este [Valdemort] não deve ser chamado por seu nome tabu, mas eufemisticamente por 'Você-Sabe-Quem." (Folha de S. Paulo, 27/08/00, Caderno Mais!, p.21). 
(14) "os cata-mendigos do Estado (...) espantaram os sem teto para a Av. Atlântica..."(O Globo, 27/08/00, Segundo Caderno, p. 3).

(15) "A migração de consumidores favoreceu o setor de eletroeletrônicos. " (Folha de S. Paulo, 27/08/00, cad. B1).

(16) "De automóveis de luxo a DVDs (Digital Video Disc), de aparelhos de TV a eletroportáteis populares, o consumidor tem se mostrado mais ávido por novos produtos."(Folha de S. Paulo, 27/08/00, cad. B1).

\section{Conclusão}

A entrada em circulação de uma nova palavra em uma língua deve atender de alguma forma às necessidades morfo-sintático-semântico-estilísticas dos falantes, de modo a justificar o seu investimento em uma nova cédula linguística. Esse investimento, por sua vez, significa um determinado esforço de memória e de raciocínio na aprendizagem da forma, função, significado e uso da moeda-palavra. Por outro lado, pela exiguidade de casos de neologismos fonológicos correntes nas línguas de modo geral, presume-se que o montante do gasto mental por palavra é considerável a ponto de os falantes evitarem as palavras totalmente inéditas, preferindo as palavras complexas. Isso porque elas já trazem em sua estrutura uma base de uso consagrado na língua, que funciona como uma pista mnemônica para que o falante possa inferir seu significado, amortizando assim uma parte do seu custo de memória.

Tais consideraçóes são pertinentes quanto à função da palavra composta, que tem sua razão de ser na nomeação e caracterização dos seres de maneira particularizada. E isso ela faz aludindo a um determinado traço de similaridade ou de contiguidade daquilo que está sendo nomeado. Essa alusão às características do denotatum pode ser chamada de mecanismo mnemônico, respectivamente, metafórico e metonímico da composição. Pode-se dizer, com isso, que o motivo da produtividade das formaçôes compostas é que elas se prestam à formação de denominações metafórica ou metonimicamente motivadas, mnemonicamente eficientes, contribuindo assim para a economia linguística. 


\section{Referências}

AZEREDO, José Carlos. Gramática Houaiss da Lingua Potuguesa. 2. ed. São Paulo: Publifolha, 2008.

BASÍLIO, Margarida. Teoria lexical. São Paulo: Ática, 2007.

BAUER, Laurie. English word-formation. Cambridge: Cambridge University Press, 1983.

FERREIRA, Aurélio Buarque de Hollanda. Novo Aurélio Século XXI: o dicionário da língua portuguesa. 3. ed. Rio de Janeiro: Nova Fronteira, 1999.

GUILBERT, Louis. La creativité lexicale. Paris: Larousse Université, 1975.

HALLIDAY, M. A. K. An introduction to Functional Grammar. London: Edward Arnold, 1985.

LAKOFF, George; JOHNSON, Mark. Metáforas da vida cotidiana. Campinas: Mercado das Letras; São Paulo: Educ, 2002.

LE GUERN, Michel. Semântica da metáfora e da metonímia. Porto: Livraria Telos, 1973.

PASCHOAL, Maria Sofia Zanotto de. Em busca da elucidação do processo de compreensão da metáfora. In: PONTES, Eunice (Org.). A metáfora. Campinas: Editora da UNICAMP, 1990.

RICOEUR, Paul. A metáfora viva. São Paulo: Loyola, 2005.

SANDMANN, Antônio José. Morfologia lexical. São Paulo: Contexto, 1992.

\section{Corpus}

FOLHA de S. Paulo. São Paulo, 27 ago. 2000; 28 ago. 2000.

GAZETA Mercantil. São Paulo, 25, 26, 27 ago. 2000.

JORNAL DO BRASIL. Rio de Janeiro, 27 ago. 2000; 16 jan. 2001; 22 mar. 2001; 28 mar. 2001.

O ESTADO de S. Paulo. São Paulo, 27 ago. 2000.

O GLOBO. Rio de Janeiro, 27 ago. 2000.

VEJA. São Paulo: Abril, ano 34, n.14, 11 abr. 2001; ano 34, n.15, 18 abr. 2001; ano 34, n.17, 2 maio 2001.

Recebido em 21 de março de 2010. Aprovado em 2 de agosto de 2010. 